Brandeis $\mid$ urearar

brandeis.edu/j-caste
CASTE: A Global Journal on Social Exclusion

Vol. 2 No. 2 pp. 359-374

October-November 2021

ISSN 2639-4928

https://doi.org/10.26812/caste.v2i2.230

\title{
Tending Immanence, Transcending Sectarianism: Plane of Mixed Castes and Religions
}

\author{
Roshni Babu'
}

\begin{abstract}
The attempt in this article is to extrapolate the notion of hybridity latent in B.R. Ambedkar's reflections on mixed castes, and outcastes, which subsequently leads to the causal link that he then derives gesticulating to social evils, namely, the origin of untouchability. Whether this embryonic notion of hybridity present in Ambedkar's work is amenable to the extrapolation of Dalit identity thought along the lines of Gilles Deleuze's notion of "immanent mixtures" is a thread that this study pursues. This certainly has broad implications for the prevalent notions of Dalit identity. This study ventures to read Ambedkar's work, Riddles in Hinduism (1987) alongside Deleuze, probing into the intuitive link between notions of hybridity and the plane of immanence.
\end{abstract}

Ideological distancing from predetermined categories of identity considered to be reductive in nature by the intellectuals of Indian philosophical thinking view such predetermined notions as facile conceptions that run short of representative qualities of complex and varied particularities of reasoned engagement with one's resources. Amartya Sen heralded this ideological position in his work titled, The Argumentative Indian (2006), in favor of heterodoxy and reasoned choice determining priorities between different identities. Lacunae regarding identification of resources prominent in Sen's work is pointed out by Jonardon Ganeri, who hails from the cluster of contemporary Sanskritists competent in philological and theoretical exegesis of "sastric" philosophical literature from the classical period of India.

This study is a close reading of Jonardon Ganeri's concept of 'resources within' which he develops in his work, Identity as Reasoned Choice (20I2) to examine the potentiality of this concept to advance a theoretical framework that could counter a sectarian view of Indian tradition, as it is professed at

'Independent Researcher (PhD, IIT Bombay)

E-mail: roshni.babu@yahoo.com

(C) 202I Roshni Babu. This is an open access article distributed under the terms of the Creative Commons Attribution License, which permits unrestricted use, distribution, and reproduction in any medium, provided the original author(s) and source are credited. 
the outset of his work. Sectarianism, which Ganeri opposes, identifies mysticism to be its chief trait which he shows to be selectively usurping only those resources grounded in Vedantic wisdom from India's past.

\section{Keywords}

Ambedkar, mixed-castes, half-castes, outcastes, Dalits, plane of immanence, Deleuze and Guattari, Ganeri, Indian philosophy, hybridity, post-colonialism

\section{I}

The attempt in this paper is to extrapolate the notion of hybridity latent in B.R.Ambedkar's reflections on mixed castes, and outcastes, which subsequently leads to the causal link that he then derives gesticulating to social evils, namely, the origin of untouchability. Whether this embryonic notion of hybridity present in Ambedkar's work is amenable to the extrapolation of Dalit identity thought along the lines of Gilles Deleuze's notion of "immanent mixtures" is a thread that this paper pursues. This certainly has broad implications for the prevalent notions of Dalit identity. Present paper ventures to read Ambedkar's work, Riddles in Hinduism (1987) alongside Deleuze probing into the intuitive link between notions of hybridity and the plane of immanence.

The notion of "hybridity" has a distinctive nexus to the advent of postcolonial reason in India. This article is an attempt to make the Deleuzean motif of "immanence" amenable to understanding postcolonial engagement with the notion of hybridity in general, and the idea of "Dalit" identity in particular in the background of Ambedkar's observations on the mixtures of castes and religious identities springing forth amidst the nominal Hindu identity. The task that calls for a new understanding of "hybridity" in the background of Dalit movements in postcolonial India is significantly different from its original locution as migratory form of selfhood in Homi Bhabha's work (Bhabha 1994). This study is an analysis of an argument that emerged into prominence in the post-independent Indian philosophical thinking which can be encapsulated in the phrase, 'one's identity is a work of reason' by which is meant that 'identity is something one actively and deliberately chooses' (Ganeri, 2012: viii). Emanating from the oeuvre of intellectuals of 'new reason' (Ganeri, 2011) this argument is developed in favor of 'multi-cultural, multi-religious, and multi-racial' societies. The anti-thesis of this argument is the notion of 'identity as something merely given by birth'. This article is a close reading of the interiors and exteriors of this "new reason". Signaling one's access to multiple sources of identity, the intellectuals of new reason resuscitate resources for the articulation of "new reason" from India. Jonardon Ganeri, prominent theorist of new reason, articulates 'identity as reasoned choice':

Using theory retrieved from India, my claim will be that identities are fashioned from exercises of reason as derivation from exemplary and paradigmatic cases, that it is procedures of adaptation and substitution from what I will call 'local norms' which is distinctive of the rational formation of an identity. (Ganeri, 2012: viii) 
Ganeri identifies 'adaptive model' as a distinctive model popular among Indian rationalists (of classical Indian Philosophical tradition). Adaptive model of reason relies on 'exemplary cases' for its normative appeal. As exemplarity of such cases are context-specific, he designates these norms as "local". One of the ostensible aims of intellectuals of new reason in developing Indian models of reasoning is to make it viable to platforms of 'global governance and cosmopolitanism' (Ganeri 2012: ix). Aakash Singh Rathore furnishes an incisive analysis of the agenda of 'deparochialization' that emerges within the framework of global justice debate that appears in the political theory developed by Amartya Sen in his work, The Idea of Justice (2009). However, Rathore's study shows its inadequacy to address the quandaries of "social justice", articulated as one among the key concerns by the Dalit Marxists (Rathore 2017; Cybil 2019). An idea of "overlapping consensus" for the peaceful resolution of conflicts is central to the theories of global justice (Ganeri 2012: ix). Conflict of interests observed to be occasioned by 'diversity of religious affiliations in democratic secular governance' is the theoretical premise of this global appeal for models of consensual reasoning disposed toward deparochializing global theoretical frameworks of reasoning.

Ideological distancing from predetermined categories of identity considered to be reductive in nature by the intellectuals of Indian philosophical thinking view such predetermined notions as facile conceptions that run short of representative qualities of complex and varied particularities of reasoned engagement with one's resources. Amartya Sen heralded this ideological position in his work titled, The Argumentative Indian, in favor of heterodoxy and reasoned choice determining priorities between different identities (Sen, 2006). In particular, this position holds itself against the historical position that regards identity as a matter of discovery. As he explains, though choices are always made within certain constraints, the point at issue is whether 'we have choices over alternative identities or combinations of identities' (Sen, 2006: 351). In arguing for an inclusionary form of Indian identity, Sen's deliberation is over the sectarian view of deriving an Indian identity from a Hindu identity (Sen, 2006: 352). Delving into the issue of congruence of Indian and Hindu identities tricks him into an evasive position forcing him to move in circles amidst traditions of heterodoxy latent to Hindu culture evidenced by the classical Sanskrit literature (Sen, 2006: 354). Tradition of heterodoxy is hailed for the sake of nurturing multiculturalism, and plurality of identities, features identified to foster cultures of secularism and democracy as opposed to the narrow sectarian imagination of a monocultural Hindu India. An effective challenge to the conferrals of identity as to "who you are" in contrast to "who you choose to be" can be discerned only when we identify the resources and methods of reasoning that could augment traditions of heterodoxy and modes of dissent from sediments of traditions (both orthodox and heterodox to invent newer forms of heterodoxies). Epistemological and ethical limitations concerning egalitarian notions of identity that would plague the notion of discovered identity would persist if we leave unattended varied modes of recognizing dissent that could support the future of heterodoxy. As we know, decisive choices involving adoption of newer definitions of identities are simultaneously departures or dissent from the conferred ones. Instances of dissent and argumentation with tradition such as we see in the works of B.R. Ambedkar whose decisive choices to depart from conferred identities undergo the agonizing process of inventing newer forms of egalitarian associations. A significant question is whether contemporary philosophical thinking in India could draw insights from the newly emergent identities such as "Dalits", "Navayana- 
Buddhists", "Adi-Sudra", or "Adi-Dravida” in such a manner as to radicalize ways of imagining egalitarian thought, its ethical underpinnings, and epistemological horizons? In particular, this article channels insights drawn from Ambedkar's exposition of the "Riddles in Hinduism", especially the one concerning "Origin of Mixed Castes" to advance prospective ways of envisioning "immanence"- as resourceful interjections into traditional resources - for the eradication of caste as a discriminative category which obstructs human potential to engage with oneself and others in meaningful and innovative modes of egalitarian associations (Ambedkar, 1987, Riddle No.18).

Lacunae regarding identification of resources prominent in Sen's work is pointed out by Jonardon Ganeri, who hails from the cluster of contemporary Sanskritists competent in philological and theoretical exegesis of "sastric" philosophical literature from the classical period of India. Though Ganeri avowedly claims to be advancing the views of B.K. Matilal, his work can be counted among the group of post-independence Indian thinkers including Daya Krishna, and J.N. Mohanty (Ganeri, 2006: 12) who fight tooth and nail to revive logical, argumentative, and rational resources from the classical Sanskrit literature against the overshadowing impact of the image of mystical India propagated by the Indian intellectuals of the colonial period namely S. Radhakrishnan, Swami Vivekananda, Krishnachandra Bhattacharyya, R.D. Ranade, A.C. Mukerji et al. (Bhushan \& Garfield, 2011). Study of logic and grammar gains importance in the works of these intellectuals of "new reason", from the period of post-independent India, who elevate these tools of reason to counter the devaluation of rational elements that arose as 'a product of the colonized Indian intellectual struggle for an indigenous, non-European identity' during the Indian nationalist movement (Ganeri, 2006: 2-3; 2016: 248-49). Their attempt to rediscover from India's past resources counterpoising the spiritual mission of the nationalist period which is perceived to have selectively usurped from India's past resources that confronted colonial intrusion, find them fashioning themselves as intellectuals of "new reason" or advocates who advance the argumentative tradition of "Navya-Nyaya" (Ganeri, 2006: 13). The argument for the promulgation of India's logical and grammatical resources from the past implies a two-pronged reasoning. One that exposes the spiritual renaissance which took place during the colonial period as a selective assortment of resources from the past to suit the purpose at hand, or a non-authentic "return to the source", and second that the rediscovery of native-culture by neo-Hindu movement was an imposition upon an emergent modernity that was underway thriving on the logical tradition of NavyaNyaya (Ganeri, 2006: 13) from about the medieval period in India. According to Ganeri, the impact of colonialism and the nativist response it triggered as manifested in the nationalist period jeopardized the emergent modernity that was otherwise earning critical acclaim from European logicians such as H.T. Colebrooke, De Morgan, George Boole, and Sir William Hamilton, et al. prior to this (Ganeri, 2006: 3-4).

Marshalling his expertise in the logical and grammatical literature from the classical "sastric" or theoretically systematized schools of philosophy, Ganeri's critical appropriation of Sen's work makes a decisive shift from Sen's focus on political figures to Ganeri's emphasis on intellectual figures who are deemed 'to have provided India with its theoretical resources' (Ganeri, 2006: 3). Identifying Sen's position to be upholding 'liberal secularism' invested in examining the 'reach of reason' as opposed to excavating the 'resources of reason', Ganeri turns his attention to the classical Sanskrit literature in Buddhism, Jainism, and Hinduism (Ganeri, 2006: 4-6). 
This study is a close reading of Jonardon Ganeri's concept of 'resources within' which he develops in his work, Identity as Reasoned Choice (2012) to examine the potentiality of this concept so as to advance a theoretical framework that could counter a sectarian view of Indian tradition, as it is professed at the outset of his work. Sectarianism, which Ganeri opposes, identifies mysticism to be its chief trait which he shows to be selectively usurping only those resources grounded in Vedantic wisdom from India's past (Ganeri, 2016: 248-249). Counter-positioning himself on the side of reason, Ganeri's work undertakes the task of detailing resources of reason from the classical Indian philosophical theories. This argumentative position which apprehends 'reason as resources', draws out its boundaries as 'resources within', whose supportive axis is constituted by the idea of 'dissent within' Hinduism, within Islam, within Christianity, and so on, thus essentializing its bounds that define the confines of "within". One of the pivotal insights that spiraled into view through Ambedkar's radical readings of Hindu-Vedic scriptures overwrite the assumed integrity of Hindu beliefs and allied practices in sustaining a unity analogous to that of other major and minor religious beliefs surrounding Christianity, Sikhism, Islam, Judaism, Zoroastrianism, etc. His critical reading of Vedic and Puranic corpus, though was impelled by the plight of untouchable communities, was equally a compelling reading unveiling the genetic code of mystical beliefs and spiritual creeds assembled under the appellation of Hinduism as essentially inseparable from its "mixtural" compounds emanating from its susceptibility to blend with other religious beliefs and systems, thus assuming the guise of resultant spiritual practices of cults. The Hinduism which Ambedkar unveils here, though is not necessarily of parasitic nature, 'is a complex congeries of creeds and doctrines that has no definite creed' (Ambedkar, 1987: Riddle No. 1: 14-15). In the Introductory chapter of Riddles in Hinduism itself he proclaims the objective of this work to be one of challenging the "Sanatan" view of Hindu civilization, a static view of Hindu religion propagated by European scholars and Brahmanic theology (Ambedkar, 1987: Riddle No. 1: 5). Against such a monocultural and static view of Hindu society Ambedkar summons the ground level or bottom-up view of Hindu belief systems emanating out of "Pir cults" (Ambedkar, 1987: Riddle No.1: 5-15). Hence Ambedkar's incisive scrutiny of Hindu scriptures and religious creeds, while on the one hand becomes a scathing attack on Brahmanic theology, on the other hand, is a probing inquiry on the future of minor religiosities as the locus of Hindu civilization. What emerges as a result of this inquiry is certainly a cross-sectional view of Hindu civilization upheld, practiced and propagated by the non-Brahmanic Hindu masses, the untouchables, and the progenies of mixed castes and religions. Hindu customs and ceremonials unveiled by this cross-sectional plane of communities of mixed origin such as Malkanas, and Matia Kunbis, Gods and Goddesses of multivalent religious fusions such as Goddess Mant Mauli, Pirana Saint Imam Shah, and Sakhi Sarwar shows that 'the beliefs of persons who are by all admitted to be Hindus often differ more widely from each other than the perceived contrast from the communities of Christians and Muhammadans' (Ambedkar, 1987: Riddle No.1: 13-14). The much-celebrated secular view of diversity gets a new verve unparalleled in its liberal versions at the hands of Ambedkar. The argument of this article terms this cross-sectionality that is coming into view as an "immanent hybridity", which opens up the "plane of immanence" onto an anticipatory scale in futuristic frame which widens the scope of imagining an anterior-hybrid religiosity of outcastes of Hinduism as an ever expanding heterodox religion of mixtures, inviting newer egalitarian dimensions at every turn. 
On a comparative axis, the present study pinpoints the loopholes lurking within the counter-sectarian approach expounded by Ganeri which fails to institute a "plane of immanence". Institution of a plane of immanence is crucial to developing a countersectarian view, it is argued, since only a plane of immanence can enunciate a plane of 'immersion' in our contemporary debates, so as to anticipate an open-ended future of events that will populate this plane. In this respect, it is crucial to differentiate the conceptual plane defining the temporal plane of our present from the plane of immanence which lays out the plane of anticipation for the future. The fact that effective anchoring in one's present defining its problematic elements of enunciation is crucial for articulating the reflective axis of philosophical thinking is overlooked in Ganeri's formulation. Situated within the intricacies of constituting a plane of immanence cutting across the contentiously inebriated and politically friable terrain of Hindu canon and ethics, we will make an attempt to pitch the plane of immanence on the unproblematized terrain of mixed castes and half-castes in religious identities. The theoretical extrapolation of the concept of immanence inspired by the work of Gilles Deleuze's and Félix Guattari's, What is Philosophy? (2003), coupled with insights from B.R. Ambedkar's study, this article engages with the conceptual issues contained in conflating the paradoxical phrase 'dissent within', and apparently innocuous phrase 'resources within'.

\section{II}

\section{Plane of immanence and creation of concepts}

Philosophical concepts are created, or rather constructed out of events that condition our pasts and presents. Nonetheless, 'philosophical constructivism', Deleuze and Guattari uphold, 'has two qualitatively different complementary aspects: creation of concepts and laying out of a plane' (Deleuze and Guattari, 2003: 36). Since concepts are conditioned by our present, and our past, the anticipation for the future that ought to be contained by the creative process can be laid out only by the constitution of a "plane of immanence".

Concepts are events, but the plane is the horizon of events, the reservoir or reserve of purely conceptual events: not the relative horizon that functions as a limit, which changes with an observer and encloses observable states of affairs, but the absolute horizon, independent of any observer, which makes the event as concept independent of a visible state of affairs in which it is brought about. (Deleuze and Guattari, 2003: 36)

In order for the plane of immanence to be independent of the creator (creator's present) of the concept, in order to take on the form of anticipation, the plane ought to anticipate a future of events, wherein such anticipation is relatively free of determination emanating in the present. In this sense, 'concepts and plane are strictly correlative' (Deleuze and Guattari, 2003: 35). In Ganeri, the notion of 'resources within' constitutes the constructive plane of immanence for the creative construction of concepts from the classical works of Hindu-Vedic canon. For those concepts to be able to reinvigorate a future, they are to be reinvented on a new plane of immanence. The plane on which they were laid out in the Vedic period no longer makes sense to us, for which reason it demands a blind faith in tradition to be the only direction in which 
its plane of immanence can be laid out. By contrast, Deleuze and Guattari underscore the significance of conceiving the plane of immanence as 'prephilosophical' as the 'foundation on which philosophy creates its concepts' (Deleuze and Guattari, 2003: 40-41). As a foundational plane, they enlist its features. While it is instituted in order to discern a direction in thinking, this plane in itself is not a concept. Rather the plane only has an 'intuitive' dimension, whereas concepts are created on this plane as 'intensions' (Deleuze and Guattari, 2003: 40-41). This intuitive plane is understood as 'prephilosophical' in the sense that its commitment towards 'nonphilosophy' is highlighted as that which sets up the internal conditions of its enunciation.

The nonphilosophical is perhaps closer to the heart of philosophy than philosophy itself, and this means that philosophy cannot be content to be understood only philosophically or conceptually, but is addressed essentially to non-philosophers as well. (Deleuze and Guattari, 2003: 41).

One of the inevitable features of 'this constant relationship with nonphilosophy', we contend, is that it is the institution of the plane of immanence that secures its anticipatory plane of openness to the other. In this respect, as Deleuze and Guattari caution, one cannot conceive the plane of immanence as immanent 'to' something because 'whenever immanence is interpreted as immanent to Something, we can be sure that this Something reintroduces the transcendent' (Deleuze and Guattari, 2003: 44-45). This is especially the case with respect to religious philosophy, or notions that have a ring of such an aura as is the case with 'faith values', 'Vedic traditions', 'Hindu canon', etc. The ideals prescribed by these notions will predetermine the direction of the discourse, in the form of regulative ideals. In order to arrest or at best escape the eruptions of transcendent onto the plane of immanence, this plane ought to be instituted on an 'infinite movement' (Deleuze and Guattari, 2003: 47-49). In philosophical terms this infinite can be marked only by 'the nonthought within thought' as 'that which cannot be thought and yet must be thought (Deleuze and Guattari, 2003: 59-60). It is in this sense that the notion of "mixtures", which in Ambedkar's enunciation assume the form of mixed castes and half-castes of religions, ought to be pitched as the plane of immanence, whereby every new understanding of one's identity in relation to Indian pasts conditioned by classical Vedic and non-Vedic scriptures, and classical and non-classical philosophical systems are pitched on a forward movement encompassing the mixtures that condition our presents and which in turn anticipates our future becomings (Deshpande 2013). ${ }^{2}$ The newly emergent communities who firmly believe in their alienation from traditional Hindu caste structures, and those who no longer want to revert or resort to the foregone privileges of that system are stranded by a lack of vision that could propel this sense of loss or alienation into a "true

\footnotetext{
${ }^{2}$ In a way, a cue for imagining a "caste-universal" that rides on the spirit of "annihilation of caste" as an alibi for secularism is contained in the observation Deshpande makes marking the advent of newly emergent communities of 'strangers' who 'begin to believe in their castelessness'.

This is the generation that is (generally speaking) distanced from the process of the conversion of traditional caste capital into secular modern casteless capital that previous generations effected. It is objectively true that in the life-experience of such individuals - who, it must not be forgotten, may still constitute a minority within their own caste-group - caste-qua-caste plays no direct role, or only a minor one... It is the double coincidence of the maturation of a sense of castelessness and the arrival of caste-marked strangers in hitherto uppercaste social milieu that confirms and amplifies this response. (Deshpande, 2013: 39)
} 
universal'. It is pertinent that we give body and volume to this universal driven by the spirit of Dalit movements in order to add substance to the otherwise thin modular notion of secularism.

Only a plane of immanence conceptualized on the grounds of mixtures can anticipate a future population of multicultural India is evident from why a reappraisal of religious or caste-based identity has to undergo and map its own journey of "reformation" before it could properly rechristen itself as "modern" (Bairy 2010). ${ }^{3}$ Notwithstanding the fact that the "secular" domain houses those who are unmarked by their caste-identity as a matter of privilege, also accommodates those who take refuge under this category despite being trapped within the caste-structure, and those who choose to be under this category as a matter of defiance, or in disguise, or in denial of being marked by a caste-identity, thus masking a broad spectrum of sentiments. This category can be transformed into a conceptual universal anticipating a future population of mixtures only when it could potentially be populated by mixtures who distance themselves from privileges of caste structure. It is in this sense that Ambedkar's reading of Manusmriti, in Riddle No.18, discussing the 'origin of mixed castes' anticipates the emergence of Dalits as a mixture of broken caste subjectivities, thus opening up the resourcefulness of such radical readings of traditions. The fact that Ambedkar comes across this fragment in Manusmriti, where Manu struggles with his census-survey to concur, on the one hand, with what goes on at the ground level of religious customs and practices of his times, and on the other hand, struggles to defer the completion of this survey in fear of political censure that might ensue from speaking the truth, is in itself a remarkable vision opened up by the plane of immanence laid out on a plane of "dissent from" classical Hinduism re-discovered in the colonial period, through concomitant appraisals by the colonial historians, Indologists, Orientalists et al., at times in service of colonial administration and governance (Dirks, 2008). For, it imparts new meaning to these ancient texts as "resources", in such a way as to step aside onto its borderlines to mark his "dissent from" it. It is true that Ambedkar is rather paying obeisance to a living tradition of dissent, whose predecessors go back in time to the time of Buddha and Sangha, Kabir, Phule, and Periyar among others (Omvedt, 2008). In this sense, his dissent anticipates newer departures from the socalled Vedic and anti-Vedic traditions of Indian pasts by finding new possibilities within its elisions. The assent-worthiness of his resourceful reading is earmarked by his shrewd labelling of Manu's list as 'perfunctory' rather than "defunct".

Repositioning Ambedkar's critical reading of Vedic corpus as resources impinges on our understanding of sectarianism. How does one define sectarianism, and how does one counterpoise oneself as anti-sectarian is an intriguing question. Ganeri signals admission of dissenting voices into one's fold as a counter-measure by which

\footnotetext{
${ }^{3}$ Inventive work done by Ramesh Bairy in this regard illuminates the trajectories of selffashioning the figure of Brahmin had to undergo in order to reinvent themselves as "modern". His point of departure is from the straw figure of Brahmin, pointing at the paucity of descriptive accounts of its 'presents'. The fact that a work that attempts to understand the real figure of Brahmin had to begin in bafflement, at its loss of resemblance in the available accounts, other than as a staple form of 'an evaluative principle overdetermined by its normativity', rather than 'as a reference to real people' (292) shows that the reappraisal of this 'absent figure of Brahmin from the present of caste' is invariably pitched on a plane of immanence, as an attempt to encompass its mediated presents and its ambivalent mixtures; see Ramesh Bairy T.S., Being Brahmin, Being Modern, 2010.
} 
we could rein in sectarianism (Ganeri, 2012: 1). In this framework, sectarianism is deemed to carry some kind of kinship or family resemblance with the so-called "tradition" and values associated with "faith", which is upheld in opposition to the idea of "dissent" which is perceived to be anchored on argument or reasoning. Juxtaposed to this, Ganeri's project develops a framework of reasoning dispelling the dichotomy between faithfulness to tradition, and openness to admission of dissent which rides on secular values:

... it is a mistake to speak of a conflict between 'secular values' and 'faith values', as if a choice has to be made between the two, for the point is to see how any faith can sustain secular principles in activities of public reasoning, equipping its adherents the resources needed to participate in deliberative democratic procedures. (Ganeri, 2012: 7).

Ganeri's anti-sectarian framework is pitched on two nodal points: (1) a project bent on appropriating 'the texts of traditional Hinduism' into the fold of resources for secular reasoning; (2) a project of 'retrieval' of Hindu religious resources, documenting its 'hidden richness and flexibility in the resources they sustain':

To be sure, the texts of traditional Hinduism are not without their welldocumented share of sectarian hyperbole, but closer inspection reveals a hidden richness and flexibility in the resources of reason they sustain. This process of retrieval of a religious culture's hidden resources is essential, I have argued, in confronting fundamentalist and dogmatic appropriations of the culture, and equally essential in countering the false claim that only with a repudiation of religious affiliation is one entitled to enter the public space of reasons of secular democratic dialogue. (Ganeri, 2012: 89)

Although theoretical and conceptual issues surrounding the notion of secular democracy peculiar to the Indian situation is not one among the issues this article takes up for discussion, in principle we would agree with Ganeri's position regarding secular democratic dialogue. Of course, one need not repudiate one's religious affiliation to enter this public space of reason, if by one's religious affiliation one also implies a persistent re-evaluation of values accrued to its faith. In fact this view currently carries wider currency in the Indian scenario, though equally debated, propelling one to examine its theoretical pillars of strengths and weaknesses. ${ }^{4}$ This theoretical project of grounding secular discourse on rational resources of religion, assumes a procedure of 'retrieval' of Hindu religious resources, for the cause of securing secular rational discourse in Ganeri. Burdened by the task of eliminating the fundamentalist and dogmatic aspects of religious dust that fell upon the rational resources, he earmarks 'accommodation of dissent', to be one of the criteria that showcases a resource's secular potential. How coherent is such an accommodation of dissent for his project of retrieval of 'resources within' is the question.

Ganeri's discussion in this work is tailored as an inventory of resources from India's past for the fashioning of identities in a multi-racial, multi-religious, and multi-

${ }^{4}$ Discussing the contextual peculiarities of Indian secularism, Rajeev Bhargava introduces the concept of 'principled distance' to illuminate upon its contextual nature which distinguishes it from its Western counterparts (85-118); whereas Anand Teltumbde contends this very postulate which claims distinctness to Indian secularism (166-193); see Secularism Under Siege (2016). 
cultural modern societies. Need for such an inventory is grounded on the justification that identity is no longer viewed in the secular discourse as 'given by birth', rather must be thought of as something which we 'actively and deliberatively choose'. Admittedly Ganeri appropriates Sen's idea that 'reason is before identity', and hence, according to them, 'neither religion, nor community, nor tradition imposes upon us an identity fixed in advance' (Ganeri, 2012: 2). Needless to say, this notion of identity when juxtaposed with contemporary identity politics, propelled by the politicization of aspects accrued to your identity by birth, as exemplified by the Dalit movement and gender politics, appears thin and formalistic. The concept of identity even when conceived in terms of becoming, exercising one's choice, 'fashioned from exercises of reason', from the available resources 'retrieved from India', presupposes freedom, which in other words mean "agency". A formalistic notion of freedom is not equipped with the tools to engage meaningfully with historically contended forms of becomings. Whether one's religious or communitarian affiliations are of significance or not cannot be determined in advance without taking into account historically acquired agency formations which directly impinge upon one's literary, political, or intellectual commitments. Viewed from the vantage point of reform movements which channelized the Indian freedom struggle, one gets a more intricate understanding of channels of freedom. Exemplary in this regard is Ambedkar's dilemma around "conversion" to Buddhism, or what may be better termed as invention of "Navayana Buddhism" - occasioned by his awareness that communitarian mobilization has a farther reach than what has been imagined by liberal humanism. Part and parcel of this political insight was also deliberations on "the historical moment of a decision unto a new name and the conditions that will make the name work' which held him back from seeking emancipation through conversion until the very last (Choudhury, 2018: 87-113; Gokhale, 2021).

Assuming the role of intellectual who has expertise in the exegetical understanding of classical Sanskrit theoretical or "sastric" resources, Ganeri devises his task to be that of presenting choices from India's classical past. Though admittedly one's identity is not 'something merely given by birth', encumbering modalities of negotiations one engages with in order to shrug off birth-based markers of caste from impinging one's freedom is a politically inebriated question around identity formations in India (Guru and Sarukkai, 2019). It follows then that it is this existentially accrued form of identities such as caste, race, ethnicity, gender, etc., that acts as a ground from which one swivels into a reflective stance. Hence, merely discounting these existential forms of identity given by birth from the corpus of creative deliberative choices will not suffice. The brunt of the caste system, and so does all the rest of social evils, is borne by those who reel beneath its hierarchical structures as differential minorities. Someone born into one of these castes will look for resources of reason that purges their suffering from the so-called Hindu canon. ${ }^{5}$

Ganeri's account subtracts aspects of identity one biologically inherits by shedding its weight onto a dissociable division of identity that distinguishes between the subjective and objective aspects which division he borrows from Akeel Bilgrami (Ganeri, 2013: 2). This dissociable notion of identity allows him to bracket the objective (biological) aspect from consideration. As we know, Dalit voice, especially

\footnotetext{
${ }^{5}$ Such an introspective inquiry by Ambedkar is entitled, Riddles in Hinduism, and at best by the titles, "The Difficulty of Knowing why one is a Hindu?" and "Manu's madness or the Brahmanic explanation of the origin of the mixed castes"; see B.R. Ambedkar: Writings and Speeches, Volume 4 (1987).
} 
in the works of Ambedkar, takes issue with the Vedic corpus as a site which undercuts objective identity. Needless to say, occlusion of objective aspects of identity from consideration has its obvious pitfalls - the resources for rational, democratic, secular discourse ostensibly extracted from the classical Indian past illusorily appear too secure and serviceable for the present.

\section{III}

\section{Resources within?}

The project intended on the expansion of the 'internal' resources of Indian theory for the sake of its development (Ganeri, 2012: ix), as expounded by Ganeri fails to define its contours of "internality" and that of "externality" of resources to be retrieved from India's past. Ganeri's project takes "internality" as a given, as transparent as the "generality" of privileged caste subjectivities, where one is at convenience to forget about the lens which enables one's view. ${ }^{6}$ The other extreme is that of outcastes or mixed castes, as explicated by Ambedkar, whereby one is at a loss to locate one's identity within the caste structure one is seemingly born into. Obtuse invisibility of one's identity within the Vedic scriptures which are otherwise upheld as manuals registering genealogies of castes legitimizing its social organizational role, on the one hand, and finding oneself trapped within it on the other, makes it imperative for the outcastes to make use of rational resources at one's disposal to articulate one's sense of loss. Today democratic discourse is fraught with tensions concerning resources for an affirmation of identity than otherwise. Given this murky situation surrounding one's claim on human rights, the identity one is born with appears to be disposable only to those who have negotiable terms within the processes of their advancement in rational discourse. ${ }^{7}$

While Ganeri places the creative element to be of central importance to philosophical thinking, he reigns in this aspect within the bounds of the notion of 'resources within', which forecloses its creative dimension to a limited set of resources, than opening it onto a limitless set of possibilities. Within such a framework, the creative aspect has to either 'adapt' itself to the requirement of past cultures (Ganeri, 2012: ix), or, 're-appropriate' the ancient tradition (Ganeri, 2012: x), within the 'permitted' limits of the "sastric" canons of classical India (Ganeri, 2012: 11), thus, attenuating its creative process. Citing John Newman, Ganeri provides a criterion to 'distinguish development and corruption within a tradition'.

\footnotetext{
${ }^{6}$ The question is, as Satish Deshpande quite insightfully asks, when does the identity into which one is born becomes irrelevant or invisible that we could dismiss it while discussing a matter such as identity formation grounded in resources of reason from India's past (32)? And for those who identifies with the caste structure, being inexplicably at the lower rungs of it in a perennial structure, 'caste appears to be the only available resource with which to try and improve the lifechances in a game where the playing field is far from level' (32); see Satish Deshpande, "Caste and Castlessness", 2013.

${ }^{7}$ This is partly because the rational discourse itself takes on the garb of 'dominant common sense' articulating the needs of 'nation building', or the task of 'modernizing our great and ancient tradition' (33). In this regard, the categories of identities that are purportedly 'unmarked' are disguised universals "invested with power, and their transparent invisibility is a sign of privilege' (38); see Satish Deshpande, "Caste and Castelessness", 2013.
} 
Newman shows that the success of a tradition is related to its ability to assimilate new data, while conserving its past principles and achievements, and also to its ability to develop complex sequences of thought and practice while anticipating future developments. (Ganeri, 2012: 196).

Further, underscoring the features of genuine development, he remarks,

If the genuine development of a tradition consists in the 'perfection' of its underlying idea and its principles, and if the possibility of such a perfection has existed from the first, then we might well expect to find... anticipations of such later developments in the earlier strata of the tradition. On the other hand, of a shift in the tradition which is not a fulfilment of its underlying idea, there will be no antecedent anticipation. (Ganeri, 2012: 197).

This idea of 'immersion' in one's past, as we can see, is unqualifiedly tilted or weighed down by the past, and hence, it falls short in weightage in its correlative notion of 'anticipation of the new'. Immersing oneself in the past with a sole criterion of 'perfection' without a commitment towards one's own present hollows out the criteria for recognition of newness, leaving the notion an easy prey to any dogmatic use, or remaining as mere rhetoric at its best. Reducing a 'situated interpreter's' (Ganeri, 2012: 226) contemporaneity to a strawman figure of secular-democratic discourse without citing the particularities of this discourse, or particular situations encountered by this interpreter is foreboded by the removal of objective aspects of identity from discussion. Complicit to this strawman figure of contemporaneity is how this notion of immersion and situatedness dissolves the idea of dissent from informing interpreter's present.

In this regard, a subtle distinction ought to be made between the 'recovery of theory' and generation of theory (Ganeri, 2012: 9). While Ganeri's own work is a concrete example of generation of theory, his plane of immanence is strictly limited to 'recovery' from a pre-existent tradition from a remote past. Since his commitment whole-heartedly relies on the 'recovery' part, the plane of immanence is not constituted by detailing the present context of enunciation.

On what grounds can we exclude the efficacy of a mode of reasoning which is modelled on an "exit", "dissent from" than "within"? Though Ganeri rightly discerns the significance of acts of dissent for the constitution of argumentative reasoning, he sidesteps his own postulate when he does not provide an adequate definition of dissent. Ambedkar's dissent being one of the paradigmatic cases of dissent in recent history, an account that purportedly honors dissent cannot sidestep similar instances for whatsoever reason unless the plane of enunciation of resources is laid out as a "limited" one (Choudhury, 2019) ${ }^{8}$.

${ }^{8}$ Probing into the constructive plane that lays out the 'common terrain' of comparable events of politics, Soumyabrata Choudhury, argues that it should be pitched on the articulation of 'historicity of the new', on the horizon of 'raw time of a new event of politics', rather than upon the historical time of the old regime (47). The historicity of the new is not to be articulated as a predetermined programme unfolding the 'analogical productivity of truth', but rather ought to be conceived as differential thinking meant to enunciate the 'imperative of an incomparable' (54). This paper enunciates the incomparable event of Mahad Satyagraha that erupts onto the comparable plane of egalitarian politics; see Soumyabrata Choudhury, "Ambedkar and other immortals", 2019. 
As a model of 'internal dissent' Ganeri cites a skeptical statement from Nyaya-sutra which argues that 'the Vedas are verifiably mistaken, internally inconsistent, and pointlessly repetitious'. The said example renders Vedic utterances as 'speech acts resembling the ramblings of a drunkard which carry no epistemological authority' (Ganeri, 2012:12). Ganeri cites this instance of dissent as exemplary of religious tolerance of Hinduism. However, the pertinent point is whether one should differentiate between the said statement found in the Nyaya-sutra from a similar statement made by Ambedkar, joining the voices of Carvaka, Brahaspati and a whole host of others whom he jointly addresses as 'indigenous' as opposed to Hindu (Ambedkar, 1987: 39). ${ }^{9}$

While there are several ways in which one discerns the generality of a concept which we may gradually render as universal, repetition is one of them. Advancing his concept of difference, distinguishing it from repeated instances, in his seminal work, Difference and Repetition, Deleuze opens a register for recording the particularities of "difference". According to Deleuze, "repetition" is often a misunderstood feature denied its own identity. Ganeri's identification of "dissent" as a characteristic feature that adds assent-worthiness to the Hindu canon is an example which denies singularity to dissent. As a result his account cannot pay heed to the dissent embodied by Ambedkar's work, Riddles in Hinduism. When we subsume repeated instances under generality, we deem those instances to be resembling each other, and hence, substitutable or exchangeable under a universal. Repetition assumes a character of its own without being dependent on generality in Deleuze's conceptualization where 'repetition as a conduct and as a point of view concerns non-exchangeable and nonsubstitutable singularities' (Deleuze, 1994:1; Patton, 2000).

The character of repetition that lends itself to singularity is earmarked by the non-repetitive aspects of festivals, celebrations, commemorations, lyrical repetition of words in a poem, etc. Within the schema of a canon or law, repetition is always recognized under two kinds of generality_perfection and integration (Deleuze, 1994: 5). In Ganeri we see the repeated instances of dissent being integrated into the notion of 'resources within' under the guise of 'perfecting' resources of reason immanent to the classical Vedic-Hindu canon.

\section{IV}

\section{Dissent from the classical Hindu corpus, assent to the post post-colonial present}

Ambedkar's rejoinder to the voice of dissent augurs the post post-colonial milieu of Indian philosophical thinking with its poignant departure from the discourse centered on East-West binary. It is for this precise reason that Ambedkar's departure is markedly post post-colonial in its double bind - first, it is not a retort to the European derision of Indian past, and thus departs from the milieu of East-West binary, the mode in which Indian philosophical dissent pivoted during the colonial period; and second, it reveals a cross-sectional view of a social phenomenon of "mixtures" which manifests itself as "the pre-philosophical plane of immanence". In particular, it is this second point of departure that poises him as a visionary of post-colonial thinking pointing towards its future.

${ }^{9}$ See B.R. Ambedkar, "Riddle No.6”, Writings and Speeches, Vol.4, 1987. 
Ambedkar's dissent from the Vedic-Hindu canon is not a negation of the Vedic pasts, rather it emerges from a sense of loss of meaning or relevance, which draws our attention to the fragmentary Manusmriti where Manu leaves the constitutive list of mixed-castes incomplete. ${ }^{10}$ Highlighting the incongruities in the list along with its incompleteness, Ambedkar insinuates how Manu's own account anticipates the looming threat of mixed-castes, whose formidable reality would make the ill-conceived Varna-system obsolete. Manu's effort to arrest the degeneration of Varna-system forebodes his step to schematize and discriminate between anuloma and pratiloma mixtures between castes, decrying the latter as degenerative (Chaudhuri, 2018).

By contrast, Ganeri's idea of 'dissent from within' is leveraged on the concept of immanence as a "limit", which is akin to Kantian idea of immanence whose lynchpin is the limit to understanding or knowledge (Smith, 2012). Kant disqualified the domain that goes outside the bounds of understanding as transcendent or dogmatic, thus reigning in the quest. Likewise, by limiting the bounds of dissent to Hindu corpus, Ganeri discounts a wide range of dialogues around argumentative dissent that ensues from the contemporary living traditions of religious practices. Among these there are practices which happen to be an offshoot of mixtures which has acquired a monstrous proportion when compared to the clean hierarchized division of caste system rediscovered by the colonial re-invention of Vedic India (Ramaswamy, 2014). In addition there are religious mixtures of Hindus with Muslims and Christians and a whole host of other religious faiths as manifest in their local variations in practices of faith. ${ }^{11}$ These phenomenon of "mixtures" call for admission of discontinuities into the notion of 'within (Hindu-Vedic corpus)'. Mixed castes, half-castes, outcasts and untouchables have fallen apart from the classical Hindu canon in a moral and spiritual sense to the point of misrecognition (Manoj, 2021). The recognition of this cross-section of society, this transversal view that Ambedkar brings into focus is the distinctive post-colonial paradigm of dissent.

What we often fail to notice is the importance of milieu that is constituted by a confluence of contingent living conditions, be it political, cultural, social, scientific, etc. Ambedkar's dissent is a manifestation of a longer battle which has been brewing for centuries emerging as "Dalit milieu" commanding assent-worthiness whereby adjoining communities constituting the least privileged in the caste system, and emergent fragmented communities, communities of mixed castes and half-castes, and half-religious minorities, communities who have been looking for a more inclusive secular platform, all find themselves clamoring to mobilize this canon under various names, whereby one of the more encompassing canopies of becoming assumes the form of becoming "Dalit". In this respect, assent and dissent are relative terms, while Ganeri's own account is an articulation of assent worthiness of classical Vedic corpus, which avowedly dissents from the canon of Enlightenment reason earmarked as the canon of Western modernity, by contrast, the Dalit milieu dissents from the classical Vedic canon harboring faith in a thinner version of Enlightenment. What it calls for is certainly a heterodox view of resources of reason, but by redefining Indian pasts.

${ }^{10}$ See B.R. Ambedkar, "Riddle No.4", Writings and Speeches, Vol.4, 1987.

${ }^{1}$ See B.R. Ambedkar, Riddle No.1, Writings and Speeches, Vol.4, 1987. 


\section{Acknowledgments}

I would like to acknowledge the invaluable inputs received from the reviewers of this article. I thank the first anonymous reviewer, and the second reviewer for their helpful comments which guided me in restructuring the paper. I thank Vinod Mishra for the editorial support extended on behalf of J-Caste. This article is dedicated to my mother A. Meenakshy.

\section{References}

Ambedkar, B.R. (1987). Riddle No. 1: The difficulty of knowing why one is a Hindu. In Vasant Moon (Ed.) B.R. Ambedkar: writings and speeches, Vol. 4, Education Department, Maharashtra, Bombay, pp. 13-15.

- (1987). Riddle No. 6: The contents of the Vedas: have they any moral or spiritual value?. In Vasant Moon (Ed.) B.R. Ambedkar: writings and speeches, Vol. 4, Education Department, Maharashtra, Bombay, pp. 37-52.

- (1987). Riddle No. 18: Manu's madness or the Brahmanic explanation of the origin of the mixed castes. In Vasant Moon (Ed.) B.R. Ambedkar: writings and speeches, Vol. 4, Education Department, Maharashtra, Bombay, pp. 215-225.

Bairy, Ramesh T.S. (2010). Being Brahmin, being modern: exploring the lives of caste today. Routledge.

Bhabha, H. (1994). Location of culture. London and New York: Routledge.

Bhargava, Rajeev (2016). Reimagining secularism: state, religion, and principled distance. In Zaheer Ali (Ed.) Secularism under siege: revisiting the Indian secular state. Delhi: Aakar Books.

Bhushan, Nalini and Garfield, Jay L. (2011) (Eds.) Indian philosophy in English: from Renaissance to Independence. New York: Oxford University Press.

Bilgrami, Akeel (2010). Note towards the definition of "Identity". In Jyotirmaya Sharma and Raghuramraju (Eds.) Grounding morality: freedom, knowledge, and the plurality of cultures. New Delhi: Routledge, pp. 43-59.

Chaudhuri, Ritu Sen (2018). Ambedkar beyond the critique of Indology: sexuality and feminism in the field of caste. In Suraj Yengde and Anand Teltumbde (Eds.) The radical in Ambedkar: critical reflections. Gurgaon: Penguin Random House.

Choudhury, Soumyabrata (2019). Ambedkar and other immortals: a note on comparative politics and incomparable events. In Cybil, K.V. (Ed.) Social justice: interdisciplinary inquiries from India. New York: Routledge.

- (2018). Ambedkar and other immortals: an untouchable research programme. New Delhi: Navayana.

Cybil, K.V. (2019) (Ed.) Social justice: interdisciplinary inquiries from India. London and New York: Routledge.

Deleuze, Gilles (1994). Difference and repetition (Trans.) Paul Patton. New York: Columbia University Press.

Deleuze, Gilles and Guattari, Felix (2003). What is philosophy? (Trans.) Hugh Tomlinson and Graham Burchill. London: Verso.

Deshpande, Satish (2013). Caste and castlessness: towards a biography of the 'General Category'. Economic and Political Weekly, 48(15), pp. 32-39.

Dirks, Nicholas B (2008) Castes of mind: colonialism and the making of modern India. Delhi: Permanent Black. 
Ganeri, Jonardon (1996). The Hindu syllogism: nineteenth-century perceptions of Indian logical thought. Philosophy in East and West, Vol. 46, No.1, pp. 1-16.

- (2012). Identity as reasoned choice. New York: Continuum.

Gokhale, Pradeep P. (2021). Classical Buddhism, Neo-Buddhism and the question of caste. London and New York: Routledge.

Guru, Gopal and Sundar, Sarukkai (2019). Experience, caste, and the everyday social. New Delhi: Oxford University Press.

Guha, Ranajit (1982) (Ed). Subaltern studies I: writings on South Asian history and society. Delhi: Oxford University Press.

Hatcher, A. Brian (2016) (Eds.). Trans-colonial modernities in South Asia. New York: Routledge.

Manoj, Rohan (Feb. 7, 2021) This isthmus of a middle state, Sunday Magazine, The Hindu newspaper.

Omvedt, Gail (2008). Seeking Begumpura: the social vision of anticaste intellectuals. New Delhi: Navayana.

Patton, Paul (2000). Deleuze and the political. London and New York: Routledge.

Ramaswamy, Vijaya (2014) (Ed.) Devotion and dissent in Indian history. New Delhi: Foundation Books.

Rathore, Aakash Singh (2017). Indian political theory: laying the groundwork for svaraj. London and New York: Routledge.

Sen, Amartya (2006). The argumentative Indian: writings on Indian culture, history, and identity. London: Penguin.

Smith, Daniel W. (2012). Essays on Deleuze. Edinburgh: Edinburgh University Press.

Teltumbde, Anand (2016). Contents and discontents of Indian secularism. In Zaheer Ali (Ed.) Secularism under siege: revisiting the Indian secular state. Delhi: Aakar Books. 